\title{
PUERTO RICO Y ESPAÑA, DOS CULTURAS, UNA MISMA FORMA DE COMPARTIR LA VIDA YLA FELICIDAD
}

\author{
Puerto Rico and Spain, two cultures, the same way of sharing
} life and happiness

\author{
Ignacio Salinas Casanova \\ Iniciativa Puerto Rico España (España)
}

Puerto Rico y España comparten una rica historia que se plasma en unos lazos culturales únicos, con el idioma español o castellano como elemento importante, así como una manera similar de entender y disfrutar de la vida, todos ellos aspectos que se enriquecen por las características distintivas de cada uno. Desde Iniciativa Puerto Rico España trabajamos con entusiasmo y dedicación para que Puerto Rico ocupe el lugar que le corresponde en la historia española, al igual que para fortalecer la presencia de la cultura española en la isla, de modo que sea percibida como un tesoro que los puertorriqueños han sabido cuidar y mejorar en estos siglos con una creatividad que ha dado la vuelta al mundo. Hablar de Puerto Rico y España es hacerlo de dos culturas, pero al mismo tiempo de una misma forma de compartir la vida y la felicidad.

Pallabras clave

Puerto Rico, España, cultura, instituciones, economía
Puerto Rico and Spain share a rich history embodied in unique cultural ties, with the Spanish o Castilian language as an important element, as well as a similar way of understanding and enjoying life, all of them aspects that are enriched by their distinctive characteristics. From Iniciativa Puerto Rico España, we work with enthusiasm and dedication to place Puerto Rico where it deserves in the Spanish history, as well as to enforce the Spanish culture presence in the island, so it can be perceived as a treasure that Puerto Ricans have cared about and improved during these centuries with a creativity that has gone around the world. To talk about Puerto Rico and Spain is to do it about two cultures, but the same way of sharing life and happiness.

Keywords

Puerto Rico, Spain, culture, institutions, economy 


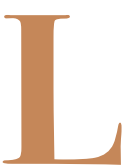

os lazos entre Puerto Rico y España son ricos y diversos, circunscritos no solo a los quinientos años de historia política compartida en los que Puerto Rico fue parte de España, sino también a un hermanamiento cultural que continúa y se refuerza día a día.

Hablar de la puertorriqueñidad es hacerlo, en cierta manera, de lazos compartidos y de un pasado (y presente) común que une a ambos países. También, por supuesto, del idioma español o castellano y de una cultura construida sobre los mismos cimientos, así como de una manera similar de entender y disfrutar la vida, todos ellos aspectos que se enriquecen por las características distintivas de cada uno, lo que permite un complemento mutuo al sumar también en el acervo común nuestras diferencias.

Los años pasan, pero permanece lo que nos acerca y fortalece, en un crisol multicolor que debería iluminar todo lo que tiene cerca, especialmente en tres ámbitos (académico-cultural, institucional y económico), respecto a los cuales deseo señalar algunos elementos ocurridos en los algo más de dos años desde que publiqué mi último artículo en la revista TSN (véase, en el núm. 5, «Puerto Rico antes y después del huracán María: el papel de la iniciativa Puerto Rico España»).

Respecto al ámbito académico-cultural, quiero destacar la importancia de la labor que la Universidad de Málaga, y concretamente el Aula María Zambrano de Estudios Transatlánticos, realiza con la organización, de momento, de dos jornadas monográficas sobre Puerto Rico. Una contribución que estimula el diálogo sincero en el marco incomparable de la academia, en el que el conocimiento histórico, sociológico y económico, así como la reflexión crítica, se unen para examinar los retos comunes y los riesgos a los que se enfrentan ambos países en un mundo tan complejo como el de hoy en día.

La celebración de estas II Jornadas sobre Puerto Rico demuestra el compromiso de la Universidad de Málaga con las relaciones transatlánticas, no siempre bien atendidas en el caso de los vínculos entre España y Puerto Rico, ya que son desconocidos por una parte importante de los españoles. Sin embargo, luchar contra ese vacío es necesario, sobre todo en un momento histórico en el que Puerto Rico se encuentra en busca de su propio destino político y el lugar que le corresponde en el panorama social y económico del siglo XXI.

Frente a las dificultades, el plano cultural y social resulta seguramente el más fructífero y agradecido. En este sentido, la Casa de Puerto Rico en España, insigne institución con más de cien años de historia, con su preciosa e imponente sede en San Juan, trabaja decididamente por mostrar y proteger la cultura española en la isla, sirviendo de lugar de encuentro de tantos y tantos españoles y descendientes de estos.
Tampoco podemos olvidar las diferentes casas regionales que existen (andaluza, balear, vasca, asturiana, gallega, canaria...) y que, si bien su labor ha sido más discreta en los últimos años, mantienen su actividad, aunque sea esporádicamente.

Desde el punto de vista institucional, nos encontramos con el principal obstáculo en el estatus político de Puerto Rico, que implica que las relaciones diplomáticas tienen lugar fundamentalmente entre España y el Gobierno federal de Estados Unidos, con el consiguiente filtro y pérdida de inmediatez que supone, algo que queda paliado, al menos en parte, por la labor del Consulado General de España en San Juan, dependiente del Ministerio de Exteriores, la Oficina Económica -en representación del Ministerio de Economía español- y la Cámara de Comercio de España en Puerto Rico. Estas instituciones trabajan para que los vínculos sean lo más directos y fluidos posible en el plano político y sobre todo económico, ya que la isla es un atractivo destino para la internacionalización de las empresas españolas.

En España, la Oficina de Turismo de Puerto Rico, situada en Madrid, lleva muchos años dedicada a dar a conocer Puerto Rico como destino turístico en España y Europa, aunque lamentablemente ha ido perdiendo financiación en paralelo con la crisis económica y financiera que azota la isla desde hace ya dos décadas.

En este sentido, desde Iniciativa Puerto Rico España sugerimos y animamos a las instituciones públicas de ambos países a que realicen un esfuerzo aún mayor para hacer visible ese sentimiento de cariño, hermandad y solidaridad que existe en el plano social. Se trata de impulsar y visibilizar una historia y una cultura para que no se sucumba ante la potencia de la cultura americana, que, si bien ha aportado importantes elementos a Puerto Rico, se ha encontrado siempre con la defensa de los puertorriqueños de sus raíces más profundas, que son, en parte, las españolas.

En España, nuestra asociación ha intentado contribuir a dar notoriedad a Puerto Rico participando en foros, conferencias y publicaciones, como las jornadas de la Universidad de Málaga o el Primer Encuentro de Descendientes de Españoles, celebrado en Madrid en abril de 2019, en el que se trató sobre la posibilidad de otorgar la nacionalidad a los descendientes de españoles en distintos países de Iberoamérica, entre ellos Puerto Rico.

El reciente relanzamiento (2019) de la Casa de Puerto Rico en España, que tuvo lugar en el marco incomparable de la Casa de América de Madrid de la mano de Rafael Pérez Colón, que coge el testigo de Ramón Darío Molinary, es una magnífica noticia. Desde entonces, trabajamos conjuntamente para impulsar cualquier acción que suponga un mayor 
conocimiento de Puerto Rico en España, como tras los terremotos que golpearon la isla en diciembre del año pasado, cuando lanzamos una campaña de información sobre instituciones a las que poder realizar donaciones, en línea con la campaña de 2017 después del huracán María mediante la cual se enviaron medicinas y productos sanitarios, así como donaciones que fueron canalizadas a través de Cáritas. A este respecto, subrayar la labor que Solidaridad para Puerto Rico desde Europa ha realizado, con la organización de eventos musicales y reuniones con el objetivo de obtener fondos para los colectivos vulnerables de Puerto Rico tras el huracán María, cuando se conformó la asociación, y los terremotos de finales de 2019, especialmente fuertes en el sur de la isla.

Amar el pasado significa proteger el presente y fijar los pilares del futuro. Ese debe ser el lema que guíe las relaciones entre ambos países. Desde Iniciativa Puerto Rico España, seguiremos trabajando con entusiasmo y dedicación para que Puerto Rico sea conocido como se merece en España y ocupe el lugar que le corresponde en la historia española. Asimismo, continuaremos velando para que la cultura española siga siendo percibida en Puerto Rico como un tesoro que los puertorriqueños han sabido cuidar y mejorar en estos siglos con una creatividad que ha dado la vuelta al mundo.

Para concluir, quiero agradecer a la Universidad de Málaga su gran labor e interés por Puerto Rico. Compartimos una misma visión: el enorme potencial para hacer más fluidas e intensas las relaciones entre Puerto Rico y España, lo cual redundará en el beneficio mutuo; porque hablar de Puerto Rico y España es hacerlo de dos culturas, pero de una misma forma de compartir la vida y la felicidad. 